\title{
Long-term seismic regime reconstruction using paleoseismological data
}

\author{
E. Rogozhin
}

Received: 6 October 2014 / Accepted: 7 November 2014 / Published online: 29 November 2014 (C) Akadémiai Kiadó 2014

\begin{abstract}
Series of geologically and seismically active ruptures with amplitudes of vertical and horizontal dislocations from some tens of centimeters up to $2.5 \mathrm{~m}$ was studied using the paleoseismological method within mobile folded systems of Northern Eurasia (the Mountain Altai and the north of the Kamchatka region) during the field works for the last decade. The paleoseismological materials have been used to estimate the seismic regime of the specified regions for the major Holocene. Micro- and macroseismic data of strong seismic events of these regions were also used, including the latest strong seismic shocks of 2003 and 2006. The results demonstrate rectilinear recurrence diagrams throughout the whole range of magnitudes in the two regions of Northern Eurasia explored. It means that the seismic regime at the Late Quaternary of the geological history has remained almost unchanged.
\end{abstract}

Keywords Magnitude - Earthquake - Intensity - Rupture - Seismic fault - Liquefaction · Active fault $\cdot$ Paleoseismology

\section{Introduction}

The seismic regime of the territory is an important characteristic of its level of seismic activity and seismic hazard. For many regions of Russia the continuance of instrumental seismological observations is short, amounts to few decades or a century (especially for the Far East and Siberia). Historical data on earthquakes are fragmentary and cover short time intervals (usually, not longer than a thousand years). Meanwhile, in many regions the strongest earthquakes recurring period extends to hundreds and even thousands of years. Therefore, it is impossible to understand a real seismic regime based only on instrumental and historical data on earthquakes. At the same time, to assess seismic risks for large federal projects such as main pipelines construction (the oil pipeline Eastern Siberia-the Pacific ocean, the gas

\footnotetext{
E. Rogozhin $(\varangle)$

Institute of Physics of the Earth, Russian Academy of Sciences,

10, B. Gruzinskaya st., Moscow 123995, Russia

e-mail: eurog@ifz.ru
} 
pipelines such as the Blue Stream, South Stream, Sakhalin-Khabarovsk-Vladivostok, the Power of Siberia and some others) one should know exactly the seismic regime of territories often feebly investigated. Therefore, it is possible to forecast the magnitude and the recurrence period in various regions using paleoseismological data alone.

For the first time in the USSR the paleoseismological methods were developed in the 1950-1960s by V.P. Solonenko and N.A. Florensov (Solonenko 1973) and applied to studying of ruptures of ancient, prehistoric earthquakes in the Transbaikal and Caucasus regions (Hromovskyh et al. 1979). All of them are based on the assumption that the strongest earthquakes of the remote often prehistoric past leave ruptures on the surface (paleoseismic dislocations). It gives a chance to check up seismic potential estimates and establish the recurrence period for strong seismic events. Afterwards, paleoseismological studies were widely adopted all over the world as the trenching, that is studying paleoseismic dislocations in trenches (Hatheway and Leighton 1979; McCalpin 2009; Pantosti et al. 1993). However, so far, it has not been quite clear how to use the trenching results to make inferences about the real seismic hazard for this or other region. As the strongest earthquakes recurrence periods revealed using the paleoseismological method vary strongly and their magnitudes also differ essentially, it is difficult to directly infer about time and force of the following seismic event in order to eventually expect the next ones in the region studied. Usually due to the trenching study scientists assess the faults activity as an average velocity of shear along the fault (in $\mathrm{mm} /$ year). But the description is an average value of the fault's activity both in geological and in seismological approaches (Paleoseismology 2009).

The paleoseismological materials have been used to estimate the seismic regime of the specific regions during the major Holocene. The author also used the data on earthquakes according to instrumental and historical seismological observations (from seismological catalogs), as well as the data on the latest 2003 and 2006 strong seismic events studied in these regions.

\section{Methods}

During seismotectonic study of different regions the author proposed to use the obtained data about paleoseismic events in different regions to define their long-term seismic regime (Rogozhin et al. 2008, 2009). The earthquakes recurrence diagram altogether with seismic activity level reflects the seismic regime of the region perfectly.

Series of geologically and seismologically active ruptures with amplitudes of one-act vertical and horizontal displacements reaching from some tens of centimeters up to several meters was studied within several mobile folded systems of Northern Eurasia (the North Caucasus, Mountain Altai, the north of the Kamchatka area and Northern Sakhalin), during the field works in the 2000th where the author participated. Motions (vertical and horizontal shifts) are most likely of impulse, seismic character. Ruptures appear not only on the surface of the ancient formations of different composition, but also in the Quaternary sediments, and sometimes even in paleosoils. There are clear-cut colluvial wedges in the ruptures zone, as well as a considerable quantity of secondary (seismogravitational and vibrational) dislocations. Sometimes, these impulse motions can be univocally related to the known strong earthquakes of the near past included in seismological catalogs, as well as to the strongest, prehistoric seismic events unknown before. The magnitude of such events was assessed using both the amplitude of the seismogenic motion, the sizes of the corresponding paleoseismodislocation field (Wells and Coppersmith 1994), and their age-according to the radio-carbon or other age determination methods. 
Paleoseismological materials allowed to estimate the seismic regime of the specific regions during the major Holocene, using also data on earthquakes of the instrumental and historical seismological observations, obtained from seismological catalogs, as well as using the data on the latest strong seismic events studied by the author in the late XX and early XXI centuries. The instrumental (catalog's) data were used for periods of representative registration of earthquakes with a level of respective magnitudes in the region under investigation. It is known that the average long-term seismic regime of a territory can be reconstructed with a statistical distribution function of frequency of the earthquakes occurrence by their magnitude, i.e. the diagram of the earthquakes recurrence (Gutenberg and Richter 1949; Riznichenko 1958). According to the methods of seismic division into districts of 1978 (Riznichenko 1980), the recurrence diagram by magnitude $(M)$ is expressed by the formula: $\operatorname{Lg}(N / T)=a-b M$, where $N$ is the quantity of events of a certain magnitude, $T$ - the time of the earthquakes occurrence, $a$ and $b$ are the intercept and slope, respectively. The results of these studies were published in a special paper (Rogozhin 2010).

\section{Detailed paleoseismic study of the strong earthquake zones}

In the early XXI century several large earthquakes occurred in Russia. Fortunately, the earthquakes were located in thinly populated areas and did not lead to human life loss. Figure 1 shows the map of earthquakes in Russia and surrounding areas. The stars indicate the most important earthquakes with $\mathrm{M} \geq 6.0$ that occurred within 2003 to 2006 and two of them are briefly discussed in this study. The Altai (27 September 2003, $M=7.3$ ) earthquake in the south part of Western Siberia was studied thoroughly. Paleoseismological investigation in the earthquake zone was fulfilled both before the event and after it.

The second strongest seismic shock occurred in the Olyutor district in the north of Kamchatka area. The earthquake happened on April, 20, 2004 in the Koriak upland, with a magnitude of $\mathrm{M}_{\mathrm{W}}=7.6$. The area of maximum shakings belongs to intensity zone 8 according to

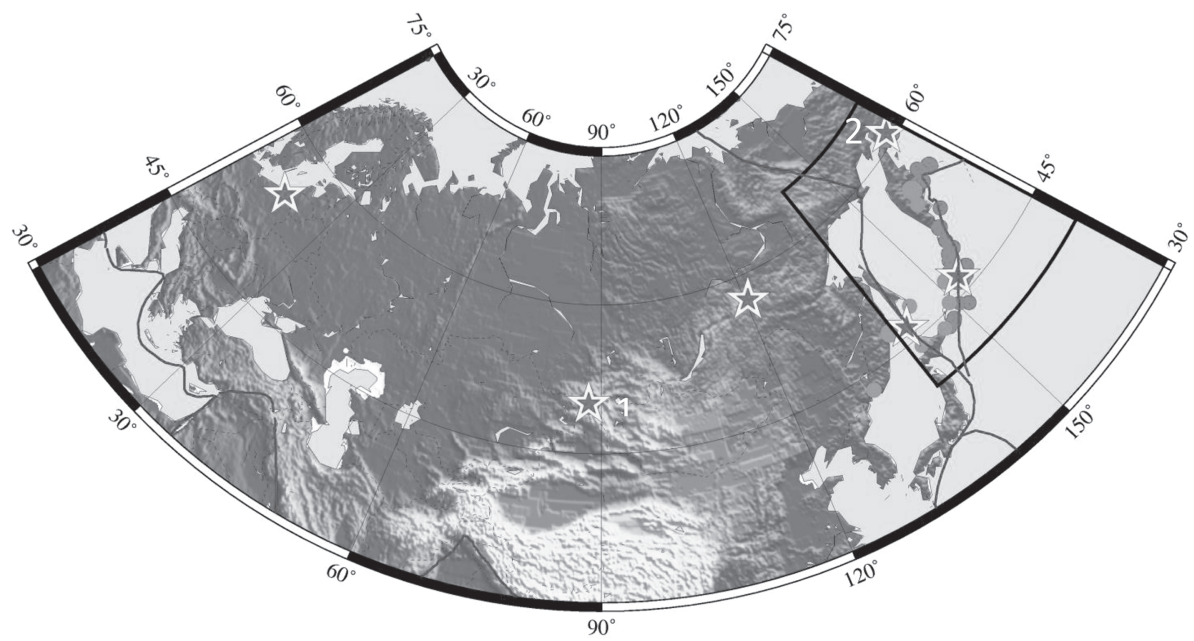

Fig. 1 Earthquakes 2003-2006 with $M \geq 6.0$ (circles) and earthquakes studied to a greater detail (stars). Grey circles indicate earthquakes of the depth of more than $80 \mathrm{~km} .1,2$-regions of fulfilled paleoseismological investigations and described in this paper (1 Altai, 2-Olyutor) 
the General Seismic Zoning Map-97 A and B (Ulomov and Shumilina 1999). The epicenter zone of the 2006 earthquake, which commonly coincides with the epicenter zone of the 1991 Khailinskiy (Koriak) earthquake $(M=7.0)$ registered in the Koriak upland to west of the Bering Sea.

After the earthquakes in the epicentral areas seismotectonic and paleoseismological study was organized. In both cases the main question was: actual earthquake was unique in the area or not and there were no such or bigger before or after the investigated event.

\subsection{Studies in the Mountain Altai}

The Mountain Altai is a typical region where, till the nineties of the XX century, the seismic history was reconstituted exclusively using instrumental and historical data over a short period of time. Therefore, it was long considered as a region with a moderate level of seismic activity. However, to south and south-east of the Mountain Altai in Western Mongolia and North-Western China the major earthquakes with a magnitude up to 8 happened in 1761, 1905 and 1931 (Solonenko and Florensov 1985). The paleoseismological studies of 1996-1998 in southern parts of the Mountain Altai showed the existence of seismic dislocations due to several strongest earthquakes $(M=7-8)$ occurred within the last 9,000 years (Rogozhin et al. 2008). Thus, the ideas about the seismic potential and the period of the strongest earthquakes which recurred in this territory were reconsidered. Atlast, in 2003 in south of the Mountain Altai, there occurred the strongest Altai earthquake with a magnitude of 7.3, which confirmed the results of the paleoseismological studies and made it possible to assess the seismic regime of the region using both the data of the instrumental, historical and paleoseismological observations, and of study of the 2003 strong earthquake. All these information sources were also used to draw up a uniform recurrence diagram.

During the 2003 earthquake kinematics in the source was a right-lateral strike-slip along practically vertical plane of northwestern or west-northwestern orientation (Figs. 2, 3a, b). The dominant type of surface faulting is a dextral strike-slip with some vertical component of normal faulting. The amplitude of seismic displacement reached $2 \mathrm{~m}$. The comparatively modest macroseismic effect and moderate gravitational seismic dislocations related to it are apparently associated with a low-frequency spectrum of the main shock seismic oscillations and a thick layer of permanent frost in the near-surface part of young sediment section. Besides the main rupture, some less extended feathering disjunctive dislocations were formed on the surface, which were of reverse fault and fault displacement type with much more moderate amplitudes of seismic displacements.

All kinds of ruptures (both primary and secondary) were excavated by trenches. Suitable samples from them (paleosoils, coals) were studied using radiocarbon method. As a result, about 25 datings were obtained .

\subsubsection{Seismic regime reconstruction using the analysis of instrumental, historical and paleoseismological results}

Till the mid 1990s there were no reliable data on earthquakes with a magnitude over 6.5 in the Mountain Altai for the instrumental and historical seismological observations. The Catalog (Kondorskaya and Shebalin 1977) indicates two events of a great magnitude: the 12.9.1761 Mongolian earthquake with $M=7.7$ (or $M=8.3$ (Solonenko and Florensov 1985)), and the 5.15.1970 Ureg-Nur one with $M=7.0$. However, within the framework of seismic zoning of 1978, the calculation of the seismic regime parameters was made with no regard to those major seismic events - apparently without the data about their recurring period. Thus, 

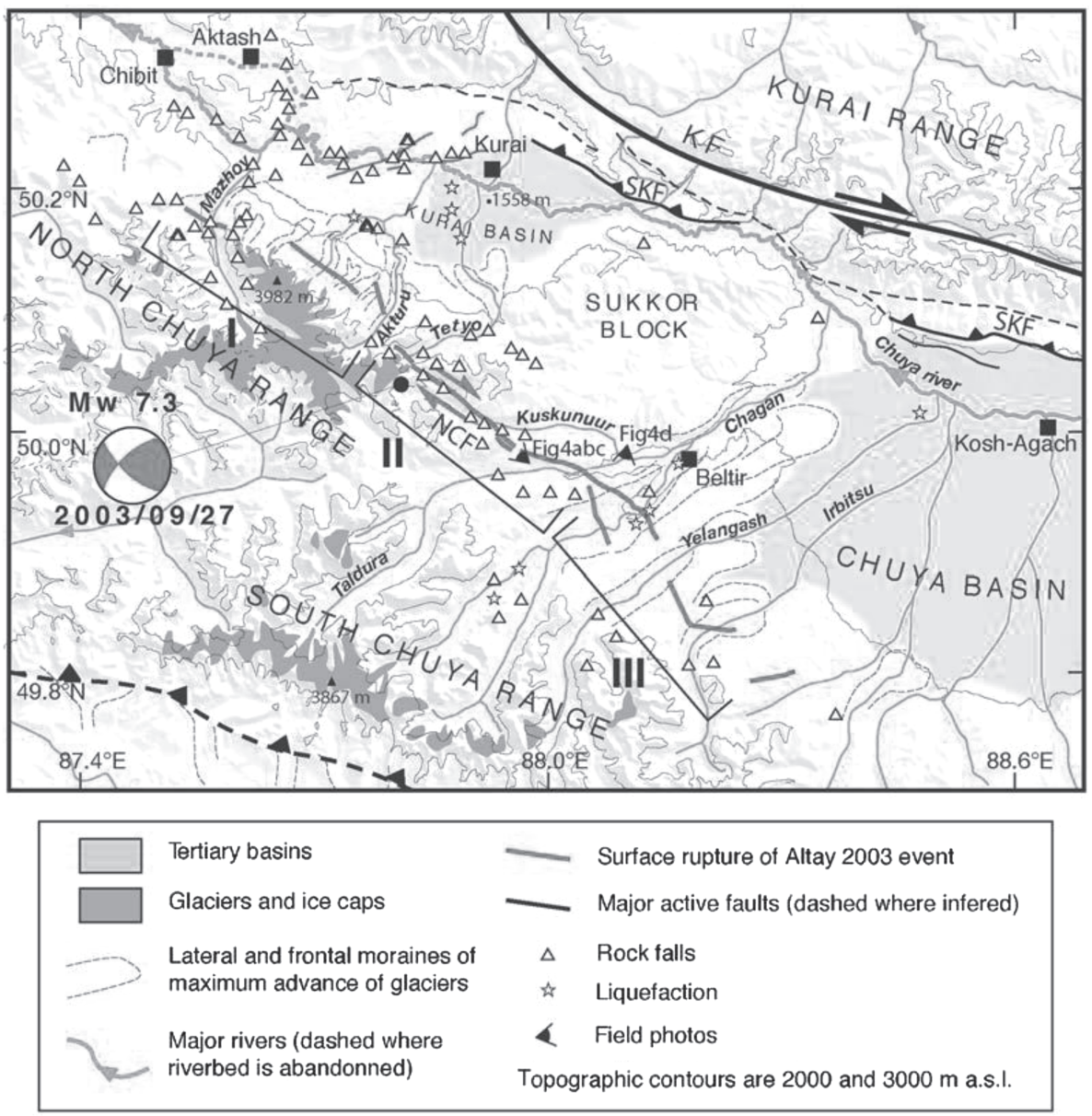

Fig. 2 Seismotectonic map of epicentral area (Dorbath et al. 2008). Main surface rupture (bold red lines) of the 2003 Mountine Altay earthquake follows the northern edge of the Chuya range along the North Chuya fault (NCF). The Chuya and Kurai basins filled with Tertiary sediments are limited north and south by growing ranges: the Kurai and Chuya mountains, respectively. The Kurai fault (KF), the major right-lateral strike-slip fault in the area, was not activated during the 2003 earthquake. We distinguish three rupture sections of the 2003 surface rupture (I, II, and III): the northwestern section along Kurai basin, the central section where the fault crosses the saddle between the Sukkor block and the Chuya range, and the southeastern section where the rupture splays into several branches. Northwest of the Kurai basin, ground breaks (thin red lines) may be secondary shaking-induced features, although they are associated with preexisting fault scarps. Focal mechanism and magnitude from Harvard CMT are also shown. SKF stands for the South Kurai fault. (Color figure online)

for the eight-intensity zone, the Map of general seismic zoning for the USSR (Bune 1980) marks the earthquakes with a magnitude $M=6.5$ as the strongest one. The recurrence graph calculation is made within $M=3.0-6.5$ for the earthquakes known according to seismological observations before 1975 .

Table 1 shows the data published by Bune 1980, where $N$ is the number of earthquakes with a certain magnitude $M, T$ - the period of observations in years. The diagram of the earthquakes recurrence calculated by orthogonal regression method is based on the data shown in Fig. 4. 
a

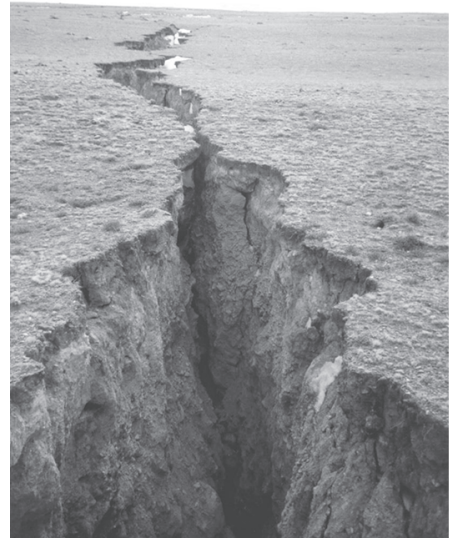

b

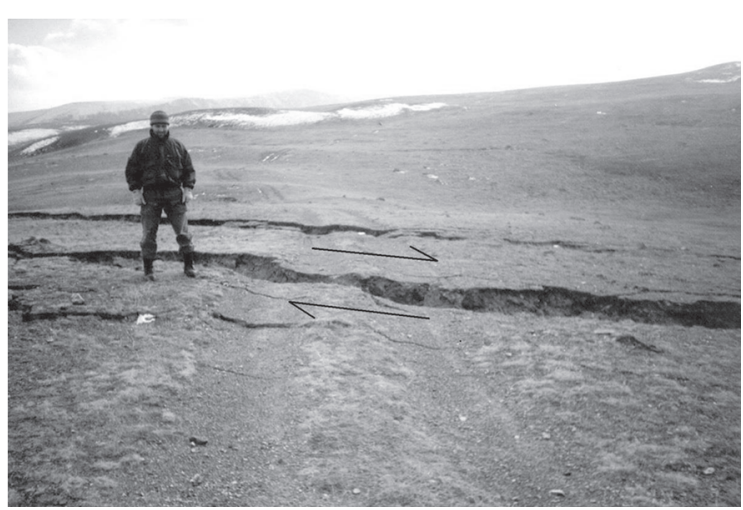

Fig. 3 Seismic fault of 2003 Altai earthquake (Photo by A. N. Ovsyuchenko): a, b different types of the rupture

Table 1 Initial data for the recurrence diagram calculation based on historical and instrumental observations up to 1975

\begin{tabular}{lllllllll}
\hline$M$ & 3.0 & 3.5 & 4.0 & 4.5 & 5.0 & 5.5 & 6.0 & 6.5 \\
$N$ & 93 & 40 & 12 & 2 & 2 & 1 & 2 & 1 \\
$T$ & 11 & 11 & 11 & 11 & 75 & 75 & 200 & 200 \\
\hline
\end{tabular}

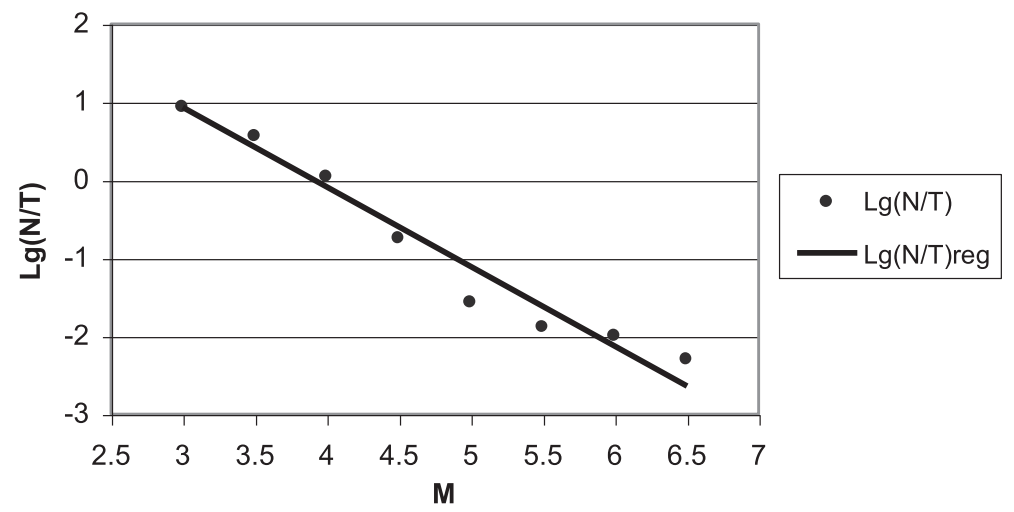

Fig. 4 The earthquakes recurrence diagram for the South Mountain Altai zone in the range of $M=3.0-6.5$ according to Table 1

In 1996-1998 in southern and southeast parts of the Mountain Altai, the primary (seismotectonic) and secondary (gravitational) seismic dislocations of several unknown earthquakes were studied in natural outcrops and trenches. They were dated using radio carbon method and their magnitude is defined not only by the length of the primary seismic ruptures and the shock displacement amplitudes, but also by the distribution area of the secondary seismic dis- 


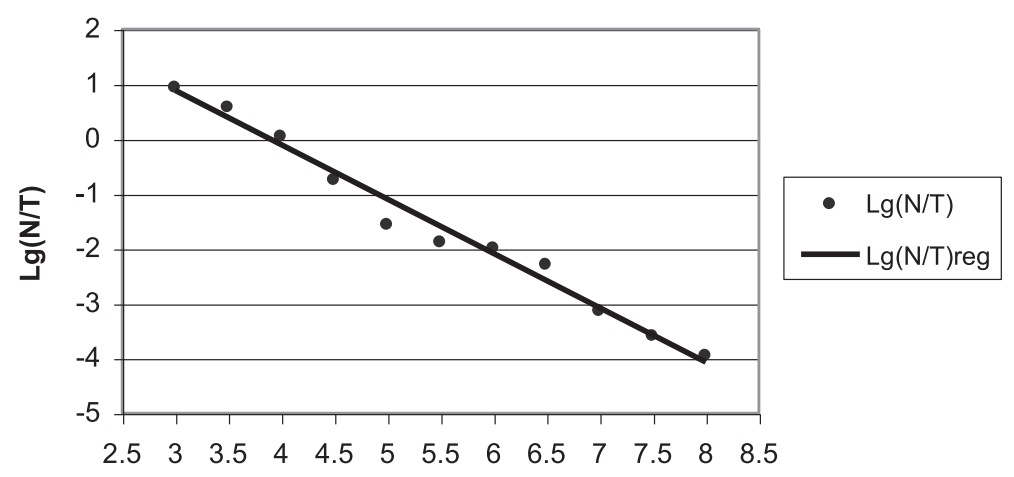

M

Fig. 5 The diagram of the earthquakes recurrence in the South Mountain Altai zone in the range of $M=3.0-8.0$ according to Table 2 and the paleo-seismological operations in 1996-1998

locations: seismic dumps, marks of liquefaction, stone avalanches and landslips (Rogozhin et al. 2008).

For Fig. 4 the dependence looks like:

$$
\begin{aligned}
\operatorname{Lg}(N / T)= & (3.99 \pm 0.62)-(1.02 \pm 0.09) M \\
& \text { at the coefficient of correlation is } R c=0.978 .
\end{aligned}
$$

In particular, the data on five ancient (Holocene) strong earthquakes with magnitudes $M \sim 7-8$ and approximate 9-10 intensity were identified for the South Mountain Altai zone. There was one event with $M=8$ within the 9,000 years period,- - two events with $M=7.5$ happened for 8,000 years and two ones with $M=7.0$ occurred for 2,600 years. One of those earthquakes with $M=8.0$ could be identified by age with the known the 12.09.1761 Mongolian earthquake with $M=7.7$ (New catalog 1977). These results were added to the initial data (Table 1) and in the magnitude range $M=3.0-8.0$ the blanket recurrence diagram was constructed (Rogozhin 2010). The graph (Fig. 5) takes into account both the results of seismological observations and of the paleoseismological study. The obtained equation is as follows:

$$
\operatorname{Lg}(N / T)=(3.86 \pm 0.39)-(0.99 \pm 0.04) M \quad \text { at } \quad R c=0.991 .
$$

The comparison of Eqs. (1) and (2) shows that correlation factors grow altogether with the increasing interval of $M$ magnitudes. Altogether with it corresponding reduction of errors in calculating the regression parameters was received. At the same time, one should note some deflection of the $L g(N / T)$ values from the average line (trend line) in the medium part of both diagrams. Apparently, it could be explained by the shortness of the instrumental observation period $T$ concerning the earthquakes of corresponding magnitudes.

\subsubsection{The seismic regime using the data of the 2003 Altai earthquake}

During the paleoseismological studies before and after the Altai earthquake, we found out that various paleo ruptures (active seismic faults, collapses and stone avalanches, impound lakes, landslips and marks of liquefaction) arose repeatedly within a short while sometimes almost synchronously in different parts of the explored region of the Mountain Altai in the course of its development in the Holocene. 


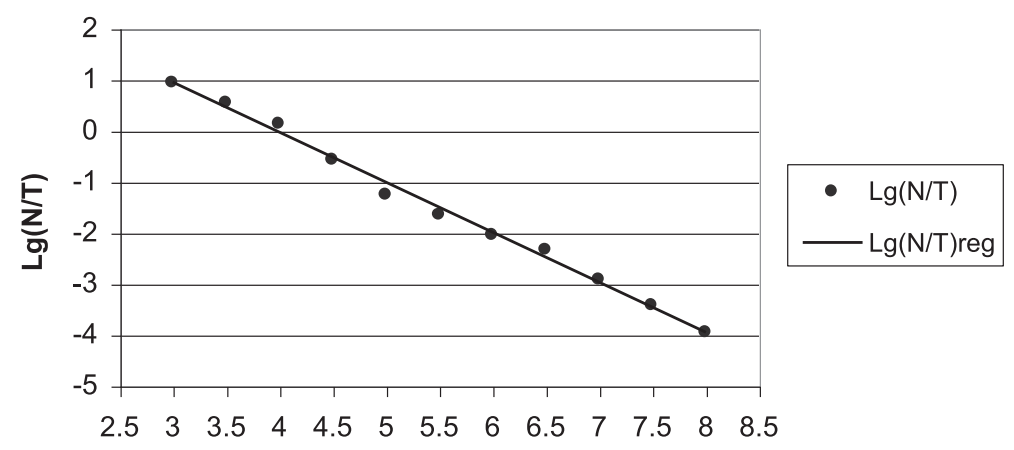

$\mathbf{M}$

Fig. 6 The diagram of the earthquakes recurrence of the South Mountain Altai zone in the range of $M=3.0-8.0$ taking into account the data on the Altai earthquake of 2003 (according to Table 3)

Table 2 Initial data for the recurrence diagram calculation on the basis of the seismological observations till 1991 and paleo-seismological information

\begin{tabular}{llllllllllll}
\hline$M$ & 3.0 & 3.5 & 4.0 & 4.5 & 5.0 & 5.5 & 6.0 & 6.5 & 7.0 & 7.5 & 8.0 \\
$N$ & 93 & 91 & 35 & 7 & 5 & 2 & 2 & 1 & 3 & 3 & 1 \\
$T$ & 11 & 26 & 26 & 26 & 26 & 90 & 215 & 215 & 2,600 & 8,000 & 9,000 \\
\hline
\end{tabular}

These time intervals are separated by the time intervals during which according to the gathered data, there was no formation of similar structures.

Strong seismic events which caused the paleoseismic dislocations occurred approximately 230-300, 1000, 1700, 2300, 3500, 4500, 5200 and 8500 years ago (Rogozhin et al. 2013). So, the average recurrence period constituted 1400 years between the earthquakes with a magnitude of about 7.0, and 2100 years between the events with a magnitude of about 7.5. The obtained periodicity is broken by the lack of seismic dislocations dating in the range of $8,000-5,000$ years ago. This possibly may be explained by the incompleteness of information on the ancient earthquakes of the first half of the Holocene. The short interval between the earthquake, which occurred about 230-300 years ago, and the 2003 Altai earthquake can be explained by the difference of their magnitude level.

Thus, the recurrence diagram (Fig. 6) for the concerned zone includes the main shock of the 2003 seismic event, with approximated $M=7.5$, and the data on the earthquakes with magnitudes of 3.5-6.5 within 1975-1990 from the Catalog (Ulomov and Shumilina 1999). The author also took into account the 5.15.1970 Ureg-Nur earthquake with $M=7.0$ and the results of paleoseismological observations. All the specified data are given in Table 2.

Figure 6 shows the earthquakes recurrence as follows from the equation:

$$
\operatorname{Lg}(N / T)=(3.89 \pm 0.21)-(0.98 \pm 0.02) M \quad \text { at } R c=0.997 .
$$

As it comes out from the Eq. (3), when adding the data on the strong earthquakes which took place in the South Mountain Altai, in particular both Ureg-Nur (1970) with $M=7.0$, and the Altai (2003) with $M=7.5$ events, the tendency of the linear correlation coefficient for the recurrence diagram is still constant, and accompanied by error value decrease. Apparently, it may testify to a good conformity of paleoseismological and instrumental seismological data. 


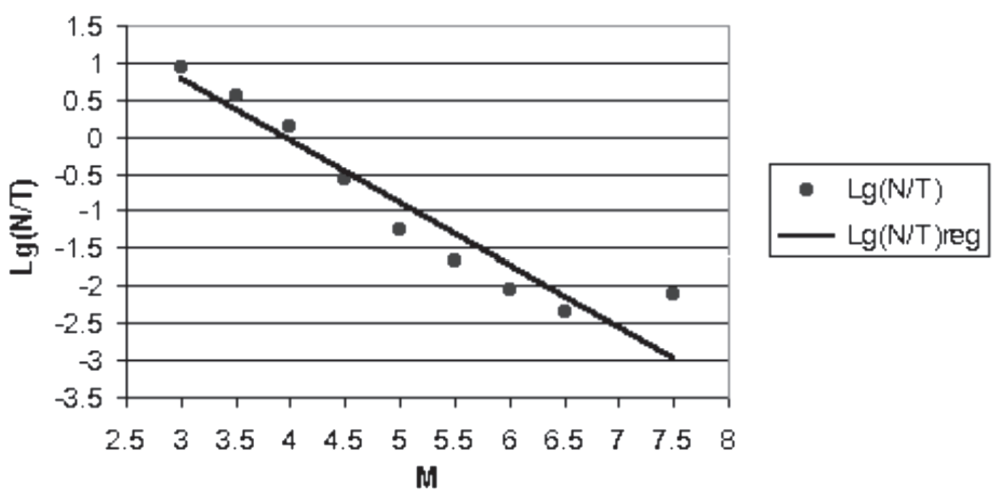

Fig. 7 The diagram of the earthquakes recurrence in the South Mountain Altai zone in the range of $M=3.0-7.5$, according to Table 3

Table 3 Initial data for calculation of the recurrence diagram based on seismological observations up to 1991, taking into account the 2003 Altai earthquake

\begin{tabular}{lllllllllll}
\hline$M$ & 3.0 & 3.5 & 4.0 & 4.5 & 5.0 & 5.5 & 6.0 & 6.5 & 7.0 & 7.5 \\
$N$ & 93 & 91 & 35 & 7 & 5 & 2 & 2 & 1 & 2 \\
$T$ & 11 & 26 & 26 & 26 & 26 & 90 & 215 & 215 & 242 \\
\hline
\end{tabular}

Comparing the recurrence diagrams in Figs. 4 and 6, one should note a special role and value of the results of search for ancient earthquakes' tracks. Due to these results it became possible to use the data of such well-known strong seismic events as the historical Mongolian earthquake of 1761 as well as the Ureg-Nur (1970) and the Altai (2003) ones to estimate the seismic regime of the Mountain Altai. Because otherwise the data on the earlier strong seismic events of 1761 and 1970 would be included in calculation neither of the diagram presented in Fig. 4 nor of the diagram in Fig. 5, as well as the data about the 2003 Altai earthquake without any information on the recurrence periods of the events with magnitudes $M=7.0-7.5$ in this zone. Without the paleoseismological data, it would be possible to use only the recurrence period of $T=242$ years for the $M=7.5$ earthquakes (i.e. the 1761 Mongolian and the 2003 Altai earthquakes) and to calculate the recurrence diagram, having added only the instrumental observations results for the events within $M=3.0-6.5$ from Table 1. As a matter of fact, such a graph (Fig. 7) can be calculated based on the data from Table 3.

The equation in Fig. 7 is as follows:

$$
\operatorname{Lg}(N / T)=(3.32 \pm 0.83)-(0.84 \pm 0.11) M \quad \text { at } R c=0.947 .
$$

It can be concluded from Eq. (4), that without paleoseismological data the errors in calculation of the corresponding recurrence diagram were substantially bigger, and the linear correlation coefficient decreased compared to those in Eq. (3).

Thus, due to the described study it follows that for the South Mountain Altai zone the most reliable earthquakes recurrence parameters are presented in Fig. 6. It is based on the complex of instrumental and historical seismological observations enriched by paleoseismological data, too. The analysis of all initial data allows ascertaining that just this diagram reflects the long-term seismic regime of the zone in the best way. Also, we can conclude that the seismic 


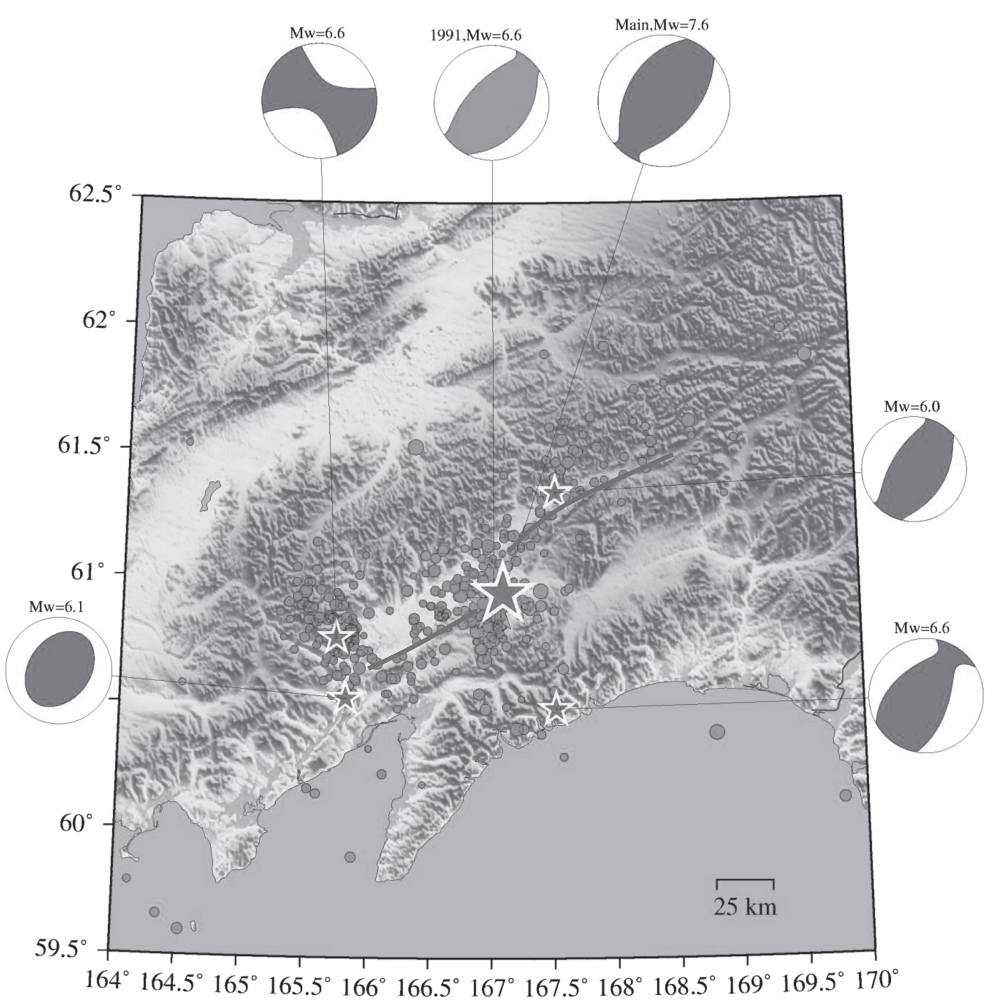

Fig. 8 The main shock and the strongest aftershocks of Olyutor earthquake (stars). The epicenters of the 2006 aftershocks are shown with red circles, shocks of 1991 are shown in violet color. Blue lines show the two largest seismic fault branches. (Color figure online)

regime of the South Mountain Altai remained almost unchanged throughout almost all the Holocene.

3.2 Results of paleoseismological investigation and long-term seismic regime of the Koriak uplands

The $M=7.6$ earthquake occurred on April, 20, 2004 in the Olyutor area of the Koriak region of Kamchatka. The epicenter zone, which considerably coincides with the epicenter area of the 1991 Khailinskiy (Koriak) earthquake, $\mathrm{M}=7.0$, was located between two large ranges of the Koriak highland (Fig. 8). The mechanism of the source is almost pure thrust. Both nodal planes are of northeastern strike coinciding with the direction of the Kuril-Kamchatka arc and the strike of the Koriak highland ranges. NEIC data show the distribution of two spatial aftershock epicenter clouds situated in two directions being perpendicular to each other (Fig. 8).

The collected macroseismic data demonstrate intensity of about 10 (according to MSK-64 scale). The results of geological studies indicate that the seismic source is an echelon-like system of seismic ruptures of the overall length of approximately $140 \mathrm{~km}$ and of general northeastern spread direction. From the kinematics of dislocations the rupture may be divided into three segments. Southwestern segment presented by a left-lateral strike-slip of some 


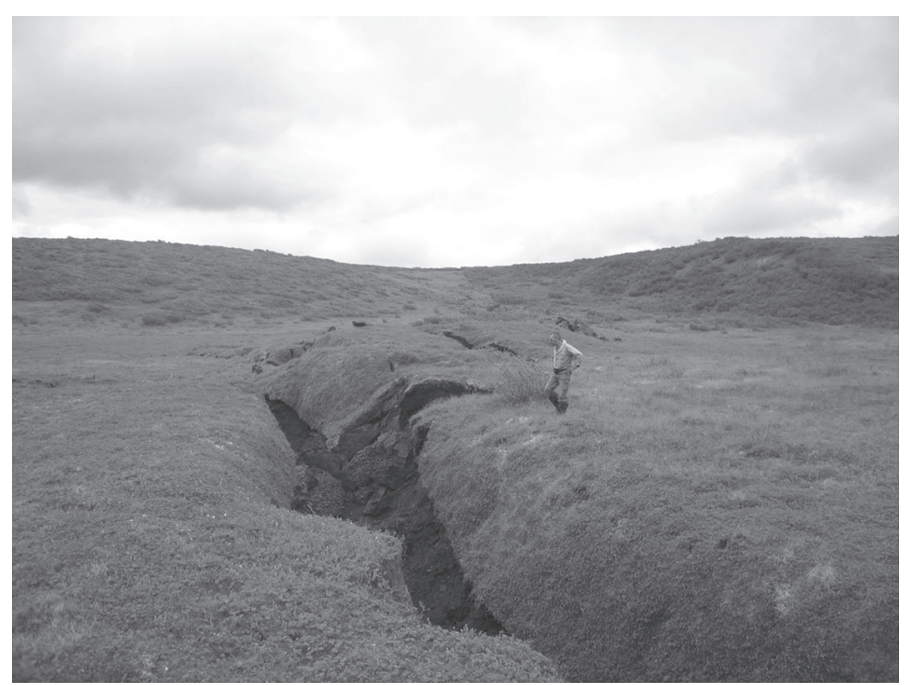

Fig. 9 Seismic trench and a bulging swell in the route of left-lateral rupture of Olyutor 2006 earthquake (Photo A. N. Ovsyuchenko)

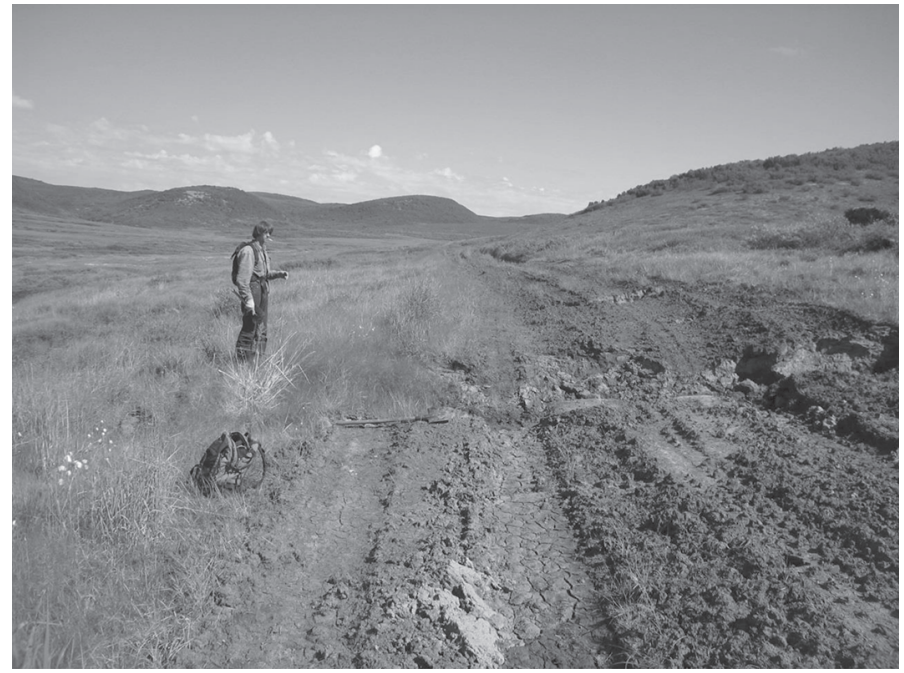

Fig. 10 Displacement of four-wheel drive vehicle road with a right-lateral rupture of Olyutor earthquake. Displacement amplitude is approximately $2.0 \mathrm{~m}$ (Photo by A. N. Ovsyuchenko)

$15 \mathrm{~km}$ long with amplitude of offset 1.6-1.8 m (Fig. 9). The central seismic fault segment is practically a pure right-lateral strike-slip. The length of this segment is about $50 \mathrm{~km}$ and offset up to $2 \mathrm{~m}$ (Fig. 10). The northeastern segment is a thrust fault with vertical displacement amplitude up to $3.0 \mathrm{~m}$ and horizontal right-lateral shift amplitude of approximately $1 \mathrm{~m}$. The length of it is approximately $75 \mathrm{~km}$.

Paleoseismological and morphotectonic observations allow us to state that the seismic rupture in 2006 is not accidental but it is linked to seismic history of the source zone that generated strong seismic events before. Their traces are fixed in numerous deformed landforms 
Table 4 Initial data for the recurrence diagram calculation based on seismological, historical and paleo-seismological data

\begin{tabular}{lllllllll}
\hline$M$ & 4.0 & 4.5 & 5.0 & 5.5 & 6.0 & 6.5 & 7.0 & 7.5 \\
$N$ & 825 & 263 & 105 & 37 & 19 & 4 & 4 & 3 \\
$T$ & 40 & 40 & 255 & 255 & 255 & 255 & 5,500 & 7,000 \\
\hline
\end{tabular}

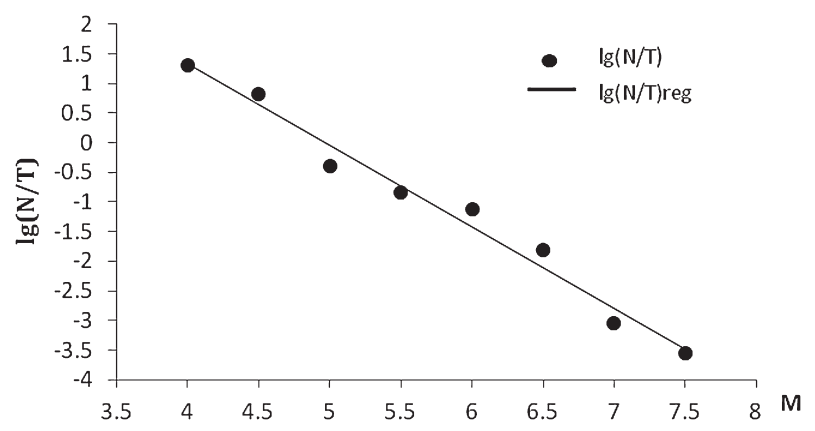

Fig. 11 The diagram of the earthquakes recurrence in the Olyutor focal zone in the range of $M=4.0-7.5$ according to Table 4

and various seismotectonic ancient structures. These structures are found in sections opened by recent seismic dislocations or swells. Several trenches were excavated and documented during the field acquisition. The reconstructed ancient earthquakes happened approximately 7000-6000, 5700-5100, 3700-3500, 2500-2000, and 1000-600 years before present. The recurrence period between the strongest events, including the Olyutor one (2006), on the average every $1,200-1,500$ years.

The recurrence graph as in previously discussed cases gives an idea about the average long-term seismic regime of the region.

The first diagram is calculated from both instrumental and historical data (Kondorskaya and Shebalin 1977; Riznichenko 1958). The diagram parameters have been calculated using the orthogonal regression method. The equation obtained is as follows:

$$
\operatorname{Lg}(N / T)=(5.90 \pm 0.75)-(1.1 \pm 0.1) M \quad \text { at } R=-0.982 .
$$

The seismological data used for the calculation of Eq. (5) were joined with results of field operations where, 3 events with $M=7.5$, were detected, including the 2006 Olyutor earthquake for the last 7,000 years, 4 events with $M=7.0$, including Khailino (Koriak) earthquake of 1991 were detected for 5,500 years (Table 4). It allowed to calculate the general earthquakes recurrence diagram (Fig. 11).

The following equation corresponds to the obtained diagram:

$$
\operatorname{Lg}(N / T)=(6.77 \pm 0.64)-(1.3 \pm 0.08) M \quad \text { at } R=-0.990
$$

Upon adding the paleoseismological data the recurrence graph slope changed, slightly reducing the average strong events recurrence period. The slope $b=-1.3$ (Fig. 11) may indicate lack of strong earthquakes in the current seismicity of the studied area during the instrumental observation period because in case of a normal regime the $b$ coefficient usually has much smaller values close to $-1,0$. One should note improvement of the overall coordi- 
nation between earthquakes magnitudes $(M)$ and their recurrence frequency logarithm $N / T$ as attested to by the correlation factor $R$ increase from -0.982 to -0.990 .

Thus, paleoseismological materials along with the instrumental and historical seismological data, have allowed us to estimate the seismic regime of the region throughout almost 7,000 years that is for the most Holocene. The obtained results can testify to the recurrence graph linearity in the explored zone of Northeast Russia. Apparently, it means that the seismic regime in the late Quaternary of the geological history covering the most Holocene remained almost unchanged.

\section{Discussion}

First of all taking into account the paleoseismological datait is clear that recent strongest earthquakes, which occurred in two regions of Northern Eurasia, were not unique events but only the last ones in the chain of the shocks with the similar magnitude in the same seismic sources. The average recurrence interval constituted about 1,400 years in the Altai's case and $1,200-1,500$ years for the North of the Kamchatka region. So, the time period is very similar.

The obtained results testify to linearity of the recurrence graphs throughout the whole range of magnitudes for the two explored zones of Northern Eurasia. It means that the seismic regime in the late Quaternary of geological history remained almost unchanged. The obtained result strikingly differs from the regional recurrence diagrams on which the General Seismic Zoning Map of Russia (GSZ-97) are based. In the area of major magnitudes, the graphs substantially deviate from the instrumentally specified ones (Ulomov and Shumilina 1999) that increases the strongest earthquakes "weight" three- fold or in the seismic regime compared to feeble and moderate shocks distribution. Apparently, it leads to overestimate the level of seismic hazard for two seismically active regions of the country.

Comparison of recurrence diagrams for the regions examined in the present section (Figs. 6,11 ) shows that variations of their slope as a whole are within the evaluation errors limits (on the average, the slope $b=-0.97 \pm 0.02$ ). Their levels somewhat differ for the Mountain Altai, and the Koriak uplands. The relative contribution of feeble and strong seismicity in case of seismic regime of the Mountain Altai region is approximately the same. The Olyutor zone of the Koriak upland shows a rather flat graph slope which somewhat increments the "weight" of minor events during the instrumental observations.

This fact allows to draw the conclusion that there are divergences between the seismic regimes of the two regions in the Holocene. That correlates with their substantial geodynamic distinctions. One could also note the high degree of correlation between the instrumental, historical and paleogeological data used in building the recurrence graphs.

\section{Conclusions}

The collected and systematized materials about ancient seismic quakes in the south of the Mountain Altai and in the Kariak region of Northern Kamchatka have let us to reconstruct the historical sequence of strong earthquake occurrence nearly for the entire Holocene. The signs of formerly unknown earthquakes with magnitudes of 6.5, 7.0, and 7.5 were found. The primary paleoseismodislocations were excavated and dated in epicentral area of both earthquakes by trenching method. The strong seismic events, which caused the paleoseismodislocations in the south of Mountain Altai, occurred approximately 230-300, 1000, $1700,2300,3500,4500,5200$ and 8500 years ago. So, the average recurrence period con- 
stituted 1,400 years between the earthquakes with a magnitude of about 7.0 and 2,100 years between the events with a magnitude of about 7.5. For the Olyutor, North Kamchatka seismically active zone ancient earthquakes, which occurred 7000-6000, 5700-5100, 3700-3500, 2500-2000, and 1000-600 years ago, were reconstituted. The recurrence period between the strongest events, including the Olutor one (2006), on the average every 1,200-1,500 years. All these novel paleoseismological data covering nearly the entire Holocene and allows the reconstruction of the long-term seismic regime for both regions. For this purpose, the recurrence plots have been constructed using the instrumental, historical, and paleoseismological data. The results obtained indicate that the recurrence graph is rectilinear in the entire magnitude range within the studied fault zones of Southern Mountain Altai and the north of the Kamchatka peninsula. This conclusion means that the seismic regime in the studied area was nearly constant throughout the Holocene of geological history. These data sharply differ from the regional recurrence graphs, which are the bases for the maps of General Seismic Zoning of Russian Federation (GSZ-97), where graph lines in the domain of big magnitudes substantially deviate from the rectilinear dependence typical for the instrumental part (Ulomov and Shumilina 1999). Thus, the share of strong earthquakes in the seismic regime is magnified threefold or even more compared to the distribution of weak and moderate events. The high degree of correlation between the instrumental, historical, and paleoseismological data, which were used for building the recurrence graph, is noted.

Acknowledgments The author is grateful to Prof. P. Varga for his interest to the trenching results in the strong earthquake zones of the Mountain Altai and the Kariak upland. The work was supported by the Russian Foundation for Basic Research (Projects 13-05-91168-a, 14-05-00091a) and by the Presidium of the Russian Academy of Sciences (Program no. 4).

\section{References}

Bune VI (1980) Map SR-78 in the USSR. In: Bune VI, Gorshkov GP (eds) Seismic zoning of the USSR. Nauka, Moscow, pp 83-97 (in Russian)

Dorbath C, Van der Woerd J, Arefiev SS, Rogozhin EA, Aptekman JY (2008) Geological and seismological field observations in the epicentral region of the 27 September 2003 Mw 7.2 Gorny Altay earthquake. Bull Seismol Soc Am 98(6):2849-2865

Gutenberg B, Richter CF (1949) Seismicity of the earth and associated phenomena. Princeton University Press, Princeton

Hatheway AW, Leighton FB (1979) Trenching as an exploratory method. In: Geology in the sitting of nuclear power plants, Vol. IV, Geologic Society of American Reviews in Engineering Geology, New York, pp 169-196

Hromovskyh VS, Solonenko VP, Semenov RM, Shilkin VM (1979) Paleo-seismology of the greater Caucasus. Nauka, Moscow

Kondorskaya NV, Shebalin NV (eds) (1977) New catalog of strong earthquakes in the USSR from ancient times until 1975 AnsScience. Russian Academy of Sciences, Moscow

McCalpin JP (ed) (2009) Paleoseismology, 2nd edn. Academic Press, Amsterdam; London

Nissen E, Emmerson B, Funning GJ, Mistrukov A, Parsons B, Robinson DP, Rogozhin E, Wright TJ (2007) Combining inSAR and seismology to study the 2003 Siberian Altai earthquakes-dextral strike-slip and anticlockwise rotations in the northern India-Eurasia collision zone. Geophys J Int 169:216-232

Pantosti D, Schwartz DP, Valensise G (1993) Paleoseismology along the 1980 surface rupture of the Irpinia fault: Implications for earthquake recurrence in the southern Apennines, Italy. J Geophys Res 98:65616577

Riznichenko YuV (1958) About study of the seismic mode. Izvestiya USSR Ser Geophys 11:1057-1074

Riznichenko YuV (1980) Seismic mode and seismic activity. In: Bune VI, Gorshkov GP (eds) Seismic zoning of the USSR. Nauka, Moscow, pp 47-58

Rogozhin EA (2010) Reconstruction of long-term seismic regime using paleoseismogeological data. In: Laverov NP (ed) Extreme natural phenomena and catastrophes. V. 1: evaluation and ways to reduce the negative effects of extreme weather events. IPE RAS, Moscow, pp 44-64 
Rogozhin EA, Jun Shen, Rodina SN (2013) Comparison of seismotectonic peculiarities of Altai Mountains and Mongolian Altai. Seism Instrum 49(4):285-296. doi:10.3103/S0747923913040063

Rogozhin EA, Novikov PP, Rodina SN (2010) Paleoseismic ruptures and the long-term seismic regime of the Koryak uplands. Geophys Stud 11(4):35-43

Rogozhin EA, Ovsyuchenko AN, Marahanov AV (2008) Strongest earthquakes in the south of the Mountain Altai in the Holocene. Phys Solid Earth 44(6):469-486. doi:10.1134/S1069351308060037

Rogozhin EA, Ovsyuchenko AN, Marakhanov AV, Novikov SS (2009) Tectonic position and geological manifestations of the 2006 Olyutor earthquake in Koryakiya. Geotectonics (6):3-23. doi:10.1134/ S0016852109060016

Solonenko VP (1973) Paleoseismogeology. Phys Solid 9:3-16

Solonenko VP, Florensov NA (eds) (1985) Earthquakes and the bases of the seismic zoning of Mongolia. Nauka, Moscow

Ulomov VI, Shumilina LS (1999) The set of maps of general seismic zoning of the Russian Federation: the SRF-97. Scale 1: 8000000 explanatory notes and a list of cities and towns located in earthquake-prone areas. UIPE RAS, Moscow

Wells DL, Coppersmith KJ (1994) New empirical relationships among magnitude, rupture length rupture width, rupture area, and surface displacement. Bull Seism Soc Am 84(4):974-1002 